\section{CHEMISTRY OF THE PROTEINS}

A

DISCUSSION meeting on the "Chemistry of the Proteins" was held by the Chemical Society in the University of Bristol on February 13. Prof. J. L. Simonsen was in the chair, in the absence, through illness, of the president, Prof. C. N. Hinshelwood. The following papers were submitted: (1) "The Integration of Physical Methods in the Elucidation of Protein Structure", by Prof. J. D. Bernal ; (2) "Modern Methods of Amino-Acid Analysis", by Dr. G. R. Tristram; (3) "The Degradation of Proteins by Proteolytic Enzymes", by Dr. J. A. V. Butler; (4) "Some Physico-Chemical Aspects of Plasma Proteins", by Dr. R. A. Kekwick.

Prof. Bernal outlined the physical methods by which information on the size, shape and crystal structure of the intact protein may be obtained. The ultra-centrifuge, with which Svedberg made the first great advance in the investigation of the gross structure of proteins, has now been shown to have certain fundamental limitations. As a method of estimating absolute molecular weights, it has probably an accuracy of 20 per cent, but it still provides accurate comparative data in investigations involving the fractionation of proteins. The electrophoresis technique introduced by Tisélius is also of great value in comparative studies, but it can do no more than separate out the different groups of proteins. Information on the shape of the protein particle has been obtained by sedimentation, viscosity and anomalous viscosity measurements and flow birefringence.

In reviowing the whole field Prof. Bernal stated that $\mathrm{X}$-rays provide the most accurate means of investigating the gross architecture of the protein crystals. Perutz and Crowfoot have demonstrated how X-ray technique may best be applied, and their work has provided much information on the crystal structure of hæmoglobin and insulin respectively. The usefulness of the technique would be extended when it became possible to carry out measurements on the protein crystal in solution.

The electron microscope is a new instrument, now in the process of development; its resolving power is now about $10 \mathrm{~A}$., and in the near future a resolving power of $5 \mathrm{~A}$. may be expected. Already many remarkable results have been obtained, and the instrument may prove to be one of the most powerful means of examining the structure of proteins.

In conclusion, Prof. Bernal suggested that the time has now come when the efforts of the various branches of protein research should be coordinated.

Dr. G. R. Tristram next outlined the means which are now available for the investigation of the aminoacid composition of proteins. Prior to 1939, most of the methods were gravimetric, required upwards of $10 \mathrm{gm}$. of protein for each analysis and yielded results upon which little reliance could be placed. In recent years, there has been a rapid development of methods, based upon many novel principles, which require very small amounts (10-100 mgm.) of protein. Among the more important of these methods are: electrodialysis for the estimation of the basic amino-acids; partition chromatography for the estimation of certain of the mono-aminoacids ; specific decarboxylases ; isotope dilution and microbiological assay. Microbiological assay, which has undergone tremendous development in the United States, and isotope dilution are capable of application to the whole range of amino-acids, although it is impossible to assess their real value because much of the work on the microbiological technique has been uncritical, and so far isotope dilution has not been widely used.

The assessment of the accuracy of any method of analysis is handicapped by the impossibility of carrying out bona fide control experiments. It is therefore suggested that each method should (i) be capable of giving reproducible recoveries when tested on ad hoc mixtures of amino-acids; (ii) that the values obtained should be reproducible; and (iii) should be capable of duplication by independent methods.

A special technique has recently been developed by Sanger which makes it possible to characterize and estimate the amino-acids which provide the terminal $\mathrm{NH}_{2}$ group(s) of the inact protein. Using this technique, much interesting information has been obtained by Sanger and his co-workers.

Insulin has now been analysed by Chibnall and his co-workers, and their chemical data suggest that the 'submolecule'. has a molecular weight of about 12,000 and contains about 106 residues (102 of which have been characterized by analysis). The work of Sanger reveals that each 'submolecule' has four chains, the terminal amino-groups of which are two residues each of glycine and phenylalanine.

The development and uses of paper chromatography were outlined by Dr. A. H. Gordon. This qualitative technique makes possible the microdetection and characterization of amino-acids and peptides. It has been used by Martin and Synge and their co-workers in their work on the structure of gramicidin $\mathrm{S}$.

Dr. J. A. V. Butler suggested that another method of approach to the determination of protein structure is by partial enzymatic hydrolysis. The products of hydrolysis should have molecular weights of about 1,000. Experiments have been carried out on the action of chymotrypsin and pepsin c $n$ insulin. The initial action of chymotrypsin is to hydrolyse off about eight peptide fractions, molecular weight $c .700$, leaving a fairly massive core having a mean molecular weight of about 5,000. The latter is still precipitable by trichloracetic acid and is therefore easily separated. It contains the greater part of the cystine. Pepsin, on the other hand, breaks the molecule into fragments having a mean molecular weight of about 3,000 .

It was observed many years ago that when peptic digests of insulin and other proteins are concentrated and treated with more pepsin at $p \mathrm{H4}$, substances, insoluble in trichloracetic acid, the so-called 'plasteins', are formed. This was thought to be due to a resynthesis of peptide bonds. It has now been found that insoluble material is formed when peptic digests are incubated at various hydrogen ion concentrations, even when pepsin has been inactivated. It is suggested that some of the original peptic fragments still retain much of the order of the original protein and, when heated and treated in other ways, undergo changes similar to those which occur in protein denaturation, giving rise to an insoluble product.

Dr. R. A. Kekwick outlined methods of protein preparation with special reference to the plasma proteins. Although it is possible to isolate proteins by electrophoresis, the amounts obtained are necessarily limited. The method is of great value, however, for the control of fractionation procedures. 
The solubility of a protein in aqueous solution depends upon $p H$, salt concentration, temperature and total protein concentration. Cohn studied the fractionation of plasma proteins with ethanol and established that, provided the temperature is maintained between $0^{\circ}$ and $-10^{\circ}$ C., a further variable, the reduction of protein solubility by means of solvents, may be introduced with great advantage.

In the past, the application of electrophoresis and the ultra-centrifuge have been the main criteria for the purity of protein preparations. As Prof. Bernal pointed out, these methods are not adequate for the assessment of absolute purity. It is now generally agreed that the final test for purity of any protein should be the estimation of solubility, that is, the solubility should be independent of the amount of protein present in the solid phase.

\section{THE MATHEMATICAL ASSOCIATION}

\section{ANNUAL MEETING}

AENERAL meeting of the Mathematical Association was held at the Polytechnic, Regent Street, W.1, during April 9 and 10, under the presidency of Mr. W. F. Bushell, head-master of Birkenhead School.

Mr. Bushell covered a wide field in his presidential address, "A Century of School Mathematics", giving a comprehensive and detailed account of the changes which have revolutionized the teaching of school mathematics in England during this period. The general level of mathematical teaching in midVictorian times was described by means of much instructive and entertaining material drawn from the two famous inquiries commonly known as the Clarendon Commission and the Endowed Schools Commission. By 1871, the sterility of a dull routine of a little arithmetic, algebra and Euclid, with no attempt to relate these topics to everyday life, was generally recognized by teachers; but the Association for the Reform of Geometrical Teaching (now the Mathematical Association), founded by Levett (King Edward School, Birmingham) and J. M. Wilson (then of Rugby, later head-master of Clifton and canon of Worcester), struggled for many years with the inertia of the older universities, the influence of which on the school curriculum through exam. inations was preponderating. The work of the Association did not begin to show real fruit until the early years of the present century ; but since then, steady progress has been made towards an understanding of the proper place of mathematics in the schools and towards a mode of teaching which shall recognize the dual aspect of mathematics, as a high exercise in abstract thinking, and as a basic human element in the life of the ordinary citizen. Mr. Bushell noted that turning-points in the teaching of mathematics had occurred simultaneously with wars and crises in world affairs, the foundation of the Association for the Reform of Geometrical Teaching in 1871, the Balfour Act of 1903, and the Fisher Act of 1917 ; and he drew from this the hope that the Butler Act of 1944 would afford teachers of mathematics an opportunity for still further reforming progress.

During the afternoon of April 9, a demonstration and discussion on "The Place of Visual Aids in the
Teaching of Mathematics" was held. Mr. I. R. Vesselo showed a number of films and film strips, suggesting possible uses for such visual aids in ordinary class teaching, and Mr. G. Patrick Meredith described a general theory of 'graphics' underlying the use of such material. The discussion seemed to show that the majority of teachers are not convinced that the film material as yet available in mathe. matics is sufficiently helpful to allow it to replace blackboard and chalk. In connexion with the discussion, Mr. Vesselo had arranged a very comprehensive exhibition of visual aids, which was open during the two days of the meeting. Models, wall charts, pictures, diagrams, all bearing on the teaching of school mathematics, had been collected in large numbers, and showed how much can be done with simple and inexpensive materials.

Later, Prof. H. Davenport (University College, London) gave a paper on "The Geometry of Numbers", in which he described in extremely lucid and simple fashion the way in which Diophantine problems in the theory of numbers can be solved by the application of geometrical concepts, a method due in the first place to Minkowski, and since then used and developed by many workers in this field.

The proceedings on April 10 opened with a paper from Mr. B. C. Brookes (Bedford) on "The Incorporation of Statistics into a School Course". The general opinion of teachers is in favour of such incorporation; but there are difficulties which have often proved insuperable, due, for example, to the influence of external examinations on the school curriculum. Mr. Brookes dealt with the place of statistics in a 'sixth form' curriculum and also in the general mathematical course in a school, and paid attention to the necessary detail of content, method and balance between theory and application. Members were much impressed by the sound practical suggestions put forward in this paper.

Dr. R. L. Goodstein (University of Reading) spoke on "Proof by reductio ad absurdum". He analysed the formal logic underlying such proofs, showing how they depend essentially on the logical 'law of contradiction' and 'law of the excluded middle', and by means of an example exhibited the difficulties and paradoxes which may arise. Again, by means of three simple examples he showed that a direct proof may often be not only as simple as an indirect proof, but may in general be expected to yield more precise information. He referred briefly to recent work on logic by Post and Lukasiewicz, in which many-valued logical systems are elaborated; in such systems the two values 'true' and 'false' of a proposition are replaced by three or more.

A discussion took place on April 10 on "A Unified Course in Mathematics in Secondary Schools", being in some sense a sequel to last year's discussion on mathematics in the 'modern' school. The discussion was opened by Mr. A. W. Riley (Wolverhampton), Mr. K. S. Snell (Harrow) and Miss E. Barnes (Birmingham). All three of the opening speakers stressed the need for seeing the school course in mathematics from the point of view of the child, rather than considering it as a mental discipline imposed on the child from above. All agreed that in the early stages the child's knowledge must grow out of his (or her) own needs and increasing awareness of the external world. For this purpose, mathematics should be presented not as a set of disconnected water-tight compartments labelled 'arithmetic', 'algebra', etc., but as a growing body of knowledge which will be 